\title{
Algumas inadequações pedagógicas na era da pós-verdade: a aula em colapso constituída na convicção de verdade como anulação do pensamento crítico ${ }^{1}$
}

\section{Some pedagogical inadequacies in the post-truth era: the collapsing class constituted in the conviction of truth as annulment of critical thinking}

Rogério Rodrigues*

\begin{abstract}
RESUMO
Este ensaio tem como objetivo analisar a dificuldade da transmissão do saber em ruptura com a posição dogmática perante a verdade, numa perspectiva da formação do pensamento crítico no campo escolar. A nossa metodologia investigativa encontra-se no campo da Filosofia da Educação, no sentido de interpretar o processo formativo como resultado de narrativas que se estabelecem em diversos caminhos percorridos nas práticas sociais educativas que determinam uma concepção de mundo em que os sujeitos, em grande parte, constituem-se na convicção de verdade como anulação do pensamento crítico. A principal conclusão do ensaio é que a passagem para a posição de professor como intelectual, na era da pós-verdade, não deveria ocorrer na polaridade entre aqueles que sabem e os outros que não sabem. Compreendemos que a passagem para a posição do professor, na transmissão do saber crítico, constrói-se no interior da atividade educativa e se constitui numa ressignificação dos espaços da transmissão da cultura escolar, no sentido de proporcionar a experiência vivida numa relação entre iguais. Portanto, como uma atividade de construção, torna-se presente
\end{abstract}

1 Agradeço à Universidade Federal de Itajubá (UNIFEI) e aos seus alunos do curso de licenciatura em Física, Química, Matemática e Biologia.

*Universidade Federal de Itajubá. Itajubá, Minas Gerais, Brasil. E-mail: rrunifei@hotmail.com http://orcid.org/0000-0003-2657-7302 
em diversos modos de compreensão sobre o mundo e no pleno sentido da ampliação da tolerância em face da discordância.

Palavras-chave: Professor. Educação. Emancipação. Verdade.

\begin{abstract}
This essay aims to analyze the difficulty of transmitting knowledge in a break with the dogmatic position before the truth, from the perspective of the formation of critical thinking in the school field. Our investigative methodology is in the field of the Philosophy of Education, in the sense of interpreting the formative process as the result of narratives that are established in various paths traveled in educational social practices that determine a conception of the world in which the subjects, in great part, constitute themselves in the conviction of truth as annulment of critical thought. The main conclusion of the essay is that the transition to the position of teacher as an intellectual in the post-truth era should not occur in polarity between those who know and others who do not know. We understand that the passage to the position of teacher in the transmission of critical knowledge is constructed within the educational activity and constitutes a resignification of the spaces of school culture transmission, in the sense of providing the experience lived in a relationship among equals. Therefore, as a building activity, it becomes present in different ways of understanding the world and in the full sense of tolerance expansion in the face of disagreement.
\end{abstract}

Keywords: Teacher. Education. Emancipation. Truth.

\title{
Introdução: a aula em colapso como resultado da verdade absoluta no campo pedagógico
}

Por muitos anos trabalhando na posição de professor, já pude constatar diversos tipos de manifestação de resistência dos sujeitos perante a questão da discussão do conceito como elemento de verdade no campo da cultura escolar no conteúdo e na forma de transmissão do saber.

A forma de reação do sujeito em face dos conteúdos da cultura escolar apresenta-se em diversos elementos contraditórios da verdade, o que pode destituir o sujeito do senso comum e isso seria o elemento que poderia promover a linha divisória entre o intelectual e o dogmatismo como manifestação da anulação do pensamento crítico. 
Na vida escolar dos sujeitos, podemos apontar que as formas de transmissão do saber dos processos formativos também prevalecem na compreensão das adequações pedagógicas de verdade que se apresentam no senso comum pedagógico, em que o aluno não aprende por uma falta de algo que possa promover o ensino. Portanto, não faltam explicações pedagógicas para compreender o fracasso escolar, o qual se centra na tese:

[...] de uma falta de adequação, ou relação natural, entre a intervenção do adulto e o estado psicomaturacional das crianças e dos jovens. Assim, oscila-se entre afirmações do tipo "ainda não está maduro para uma tal atividade" e o "método utilizado revelou ser pouco eficaz" [...]. Sendo essa tese da conaturalidade que funciona como algoritmo do raciocínio pedagógico, é possível escutar por aí afirmações singulares do tipo: "é por causa da falta de motivação", "porque é filho de pais separados", "porque é uma criança favelada", "porque a lousa é preta e não verde", "porque, no lugar de dar o intervalo no meio, o professor deu no fim da aula", "porque, no lugar de fazer uma aula de uma hora, fez uma aula de uma hora e meia e as pesquisas psicológicas alertam para o fato de se produzir estafa psíquica depois de uma hora" (LAJONQUIÈRE, 1999, p. 28).

Neste sentido, no campo do senso comum pedagógico, esses bloqueios pautados em verdades podem ocorrer em diversas formas de manifestações dentre as mais simples, como por exemplo: "faça o que eu mando"; "eu já fiz a lição"; "quantas linhas, professor?" - enfim, em diversos aspectos que indicam a completa anulação do pensamento crítico do sujeito. Em condições mais radicais, isso pode caminhar no sentido do confronto direto, o qual resulta em "isso não me interessa".

O que cabe destacar é que, entre as diversas formas, o que prevalece é a produção da anulação do outro na relação entre ensinar e aprender, que pode levar à completa ausência de diálogo perante a discordância. $\mathrm{O}$ principal resultado seria a impossibilidade na transmissão crítica do conceito entre o conteúdo e a forma, para se desmontar a suposta verdade estabelecida no campo escolar como elemento comum a todos.

Essa resistência no processo de transmissão do saber que ocorre entre o dizer e o escutar impede a forma do relacionamento sincero perante o conceito no campo escolar e, principalmente, o estabelecimento de determinados esforços intelectuais como forma de aproximação na reconstrução de verdade, na perspectiva do intelectual diante do paradoxo da crítica da crítica que se estabelece nas diferenças dos sujeitos na abertura do pleno diálogo. 
A impossibilidade do diálogo sobre a questão da verdade absoluta encontra-se, principalmente, na pressuposição daqueles que estabelecem um apego às certezas também absolutas e que nos tornam incapazes de produzir a tolerância perante a discórdia, numa plena redundância dos discursos que garantem o conhecimento diante da realidade.

Parece que somos vítimas das verdades que se instauram, uma vez que estas podem se instituir no paradoxo de se evitar conhecer a realidade como síntese de diversas contradições. Portanto, encontram-se dificuldades em compreender a realidade como "sínteses das múltiplas determinações" (MARX, 1983, p. 218).

Partimos do pressuposto de que a condição do exercício filosófico perante o senso comum seja, de um lado, a desconstrução da verdade, e isso seria a perda do sentido comum para que pudéssemos desbanalizar as certezas constituídas, algo comum a todos, no sentido de analisar o que é peculiar em outras narrativas em que

[...] não se propõe a enxergar a mais que outros. Ela não acredita que pode alimentar vanguardas. Ela está longe de achar que a tarefa da filosofia é "tirar o véu" do real, descobrindo sua verdade, ou acreditar que pode "fabricar" o real, produzindo sua verdade. A filosofia como desbanalização do banal não procura a "realidade por detrás da ilusão". Não há nada que se possa dizer que está atrás ou na frente. Abordamos o cotidiano como aquilo que nós vivemos corriqueiramente. Trata-se do que é mais visto e, de fato, mais conhecido entre nós. Não estamos numa Caverna. Estamos muito bem à luz do sol. Olhamos tudo e conhecemos quase tudo. Fazer filosofia, portanto, na minha acepção, não tem a ver com a atividade de uma vanguarda que enxergaria o que está abaixo ou por detrás do real, que outros não estariam vendo. No trabalho que faço, o que importa é contar uma boa história, é produzir uma boa narrativa, é contar alguma coisa sobre as nossas práticas diárias que possa ser posta na mesa, no leque das outras perspectivas que estão sendo necessariamente geradas por outros (GHIRALDELLI JR., 2011).

Nesse contexto, por outro lado, o "desbanalizar o banal" (GHIRALDELLI JR., 2011) seria sair daquilo que se representa como óbvio e comum para todos e para a crítica, no sentido de produzir outras possibilidades que também definem os elementos na construção de verdade.

Nessa dinâmica, a nossa proposição metodológica investigativa, colocando-se na posição de professor, seria destituir a verdade como elemento dogmático e intolerante, para se tentar restituir o diálogo com o outro numa 
posição do não saber, em que se alteram o conteúdo e a forma na transmissão do conceito no campo da cultura escolar.

A questão central é que, perante a verdade, temos dificuldade de encontrar o ponto comum que se estabelece na intolerância; assim, o dogmatismo torna-se presente na transmissão dos saberes acríticos em sala de aula, constituindo-a no pleno colapso do diálogo. Isso é algo que gira em torno de narrativas construídas na teimosia, que nos impedem de encontrar o contraditório presente no outro em seu modo diversificado e estranho de viver e pensar.

O ponto de contato da verdade seria a possibilidade de desbanalizar o comum (GHIRALDELLI JR., 2011), no sentido de analisar os elementos contraditórios, para se colocar em evidência as diversas situações com as quais podemos nos defrontar no cotidiano escolar, em que se possa evitar a intolerância e o dogmatismo perante o saber, no campo da cultura escolar e, principalmente, indicar isso como verdade estabelecida no campo pedagógico.

Compreendemos que o conhecimento banal que se apresenta perante o saber escolar se institui como apego de verdade. O exercício em sala de aula seria a possibilidade de desmontar esses pressupostos de verdade que se encontram presentes na concepção de mundo de cada sujeito, para se colocar em construção o pensamento crítico. A maior dificuldade na realização dessa tarefa é que a verdade estabelecida também se explica como algo comum a todos, como elemento constituído para diversos grupos de sujeitos que se identificam a partir de seus estilos de vida. Portanto, o trabalho do intelectual seria aquele que se implica com o que é comum e promove algum tipo de intervenção, no sentido de romper com o fechamento dos pensamentos e, principalmente, buscar produzir diversas outras formas de processos, que podem provocar o estranhamento do sujeito perante o seu modo de vida.

Essas proposições da alteridade em outras formas de pensar a realidade podem ampliar a experiência do sujeito e permitir que se analisem os diversos elementos da contradição, para se compreender a complexidade da realidade.

O outro maior problema também se apresenta quando a discussão do conceito como elemento clássico da cultura não avança por certa teimosia do sujeito em não querer pensar criticamente a questão da realidade, fixando-se em discursos que paralisam qualquer forma de analisá-la.

Essa condição de recusa do pensamento crítico produz certo estranhamento, que se apresenta nos diversos tipos de reações dos sujeitos e, portanto, causalhes espanto como mecanismo de não querer pensar, e isso, em grande parte, expõe algo de verdade na maneira de existir dos sujeitos, mais propriamente nas manias constituídas que nos orientam a pensar o campo escolar nas interfaces com a pós-verdade. 
Compreendemos a questão da pós-verdade como algo central para a discussão referente aos processos formativos para a construção de efetiva educação do sujeito. Temos como hipótese de trabalho que ocorre uma interdição na verdade a ser dita no campo educacional, o que Freud (2010) já indicava ao dizer:

O fato da educação atual ocultar ao jovem o papel que a sexualidade representará em sua vida não é a única censura que se lhe deve fazer. Ela também peca ao não prepará-lo para a agressão de que ele está destinado a ser objeto. Ao lançar os jovens na vida com uma orientação psicológica tão incorreta, a educação procede como se munisse com roupas de verão e mapas dos lagos do norte da Itália pessoas que farão uma expedição polar (FREUD, 2010, p. 163-164).

Diríamos que esse conjunto de disposições de ausência de verdade é também um mecanismo do sujeito para evitar a realidade. Portanto, dizer sobre o que não é dito seria papel fundamental na transmissão da cultura escolar no sentido de preparar o sujeito para a interpretação crítica da realidade e evitar o ponto cego. Entretanto, as narrativas de pós-verdade se impõem em não dizer que:

O ponto cego para o mestre explicador é contornado por um saber que busca evitá-lo, mas o conjunto das explicações apenas amplia o seu tamanho, no sentido de que o real apresenta uma dinâmica que se impõe como falta de verdade (RODRIGUES, 2020, p. 52).

Esse ponto cego como anulação da verdade pode se apresentar no aprender instrumental sem o ensinar comprometido e que em última instância se constitui naquilo que podemos denominar como sendo as inadequações pedagógicas na era da pós-verdade. Diríamos que isso se apresenta na atividade educativa na aula em colapso constituída no paradoxo, por um lado, da ausência de verdade perante a dinâmica complexa da realidade e, por outro lado, na convicção de verdade que se prende nas aparências das coisas como anulação do pensamento crítico em que "O mundo da pseudoconcreticidade é um claro-escuro de verdade e engano" (KOSIK, 1976, p. 11). 


\section{A questão da transmissão do saber crítico: elementos para se compreender o campo pedagógico escolar nas interfaces com a pós-verdade}

Podemos partir da hipótese de que a base da recusa do pensamento crítico seja a dificuldade de o sujeito lidar com a lei estruturante no campo da subjetividade, que pode se constituir no campo da psicose, como na construção do pensamento paranoico. O termo psicose

[...] foi primeiramente empregado para designar a reconstrução inconsciente, por parte do sujeito, de uma realidade delirante ou alucinatória. Em seguida, inscreveu-se no interior de uma estrutura tripartite, na qual se diferencia da neurose, por um lado, e da perversão, por outro (ROUDINESCO; PLON, 1998, p. 621).

Nesse contexto, de um lado, a relação de transmissão do saber para o sujeito no campo das neuroses se constitui na tentativa de compreender aquilo que foi enunciado e, portanto, no esforço do pensamento em se dialogar com o assunto em questão. Entretanto, por outro lado, tendo como base a psicose como forma de perda de contato com a realidade, o ponto central dessa discussão gira em torno da recusa da realização do pensamento crítico e, portanto, torna-se importante compreender o sentimento de estranhamento como algo que se produz na circunstância que se incorpora no campo das subjetividades. Seria importante compreender essa ruptura de diálogo no campo da psicose, e isso pode ser considerado importante enquanto elemento para se interpretar o conjunto das contradições que se apresentam como algo que se produza como "Nada do que é humano me é estranho" (FEDOSSEIEV et al., 1983, p. 498).

A partir dessa premissa, podemos pressupor que, no campo das relações humanas, tudo é possível, e isso seria certo conformismo quando se diz o quanto é comum os sujeitos se tornarem rudes e intolerantes perante a cultura.

Entretanto, o estranhamento pode ser algo também relacionado ao destino do desejo, uma vez que pode ser reduzido ao retorno de coisas antigas e familiares ao sujeito que se encontram reprimidas (FREUD, 1996). Nesse aspecto, pode-se compreender que isso se encontra presente em cada sujeito como uma forma de ser rude em face da cultura e que nada queremos saber sobre esse saber e, portanto, "[...] em última instância, não há saber possível sobre o desejo" (LAJONQUIÈRE, 1992, p. 226). 
Em relação ao primeiro elemento de estranhamento, como algo inerente ao sujeito, o caminho seria o de naturalizar a barbárie perante a cultura como elemento condizente à existência do sujeito. Em relação ao segundo elemento, o estranhamento é o retorno de algo reprimido por desgosto perante a cultura, o que seria, em parte, o reconhecimento do ódio do sujeito diante do processo civilizatório, que impõe ao sujeito uma contenção de suas próprias pulsões. Contudo, o destino do desejo poderia se resolver, basicamente, em três saídas, ao se alcançar os seguintes contornos para essa questão, que seriam as formas possíveis de

[...] soluções para rematar satisfatoriamente conflito e neurose, as quais, em determinados casos, podem combinar-se entre si. Ou a personalidade do doente se convence de que repelira sem razão o desejo e consente em aceitá-lo total ou parcialmente, ou este mesmo desejo é dirigido para um alvo irrepreensível e mais elevado (o que se chama "sublimação" do desejo), ou, finalmente, reconhece como justa a repulsa. Nesta última hipótese o mecanismo da repressão, automático, por isso mesmo, insuficiente, é substituído por um julgamento de condenação com a ajuda das mais altas funções mentais do homem - o controle consciente do desejo é atingido (FREUD, 1970, p. 28).

Na contenção das pulsões ou no impedimento da realização do destino suportável do desejo, por parte do sujeito, são os diversos tipos de situações que definem os motivos destes a causar aquilo que denomino, no campo escolar, ao longo da tarefa da transmissão da cultura, como sendo a aula em colapso.

Essa condição da aula em colapso pode ser promovida nas discordâncias, em que a convicção de verdade prevalece como barreira para o impedimento do verdadeiro diálogo em que as "[...] convicções são inimigas da verdade [e] mais perigosas que as mentiras" (NIETZSCHE, 2000, p. 265). A base comum presente nessas situações é a disputa de verdade como conviç̧ão que embrutece a todos, diante dos determinantes do real, na construção do conceito no campo da ciência.

Em todas essas ocasiões, o resultado desse embate é a produção do mal-estar no campo das relações humanas, em que analiso se a minha condição de autoridade de professor não prevalece como elemento que possa conduzir o processo do educar e do ensinar como elemento comum de discussão em sala de aula.

Pelo viés do dogmatismo perante a verdade, a contrapartida se estabelece em afirmar algo contra, posicionando-se como elemento autoritário, que estabelece formas de hierarquia. Entretanto, os opositores à crítica da crítica ao pensamento dogmático não se apropriam desse pensamento, posicionando-se 
em outras formas de hierarquias condizentes com posições autoritárias, que impedem o diálogo e se constituem no fechamento do pensamento em aspectos de convicção de verdade como anulação do pensamento crítico.

Essas situações produzem a inquietação em lidar com as resistências ao pensamento, pois se torna difícil lidar com palavras de efeitos e, principalmente, nos tempos atuais, torna-se complicado contrariar a ideia de que exista hierarquia e poder presente no sujeito que apresenta como exemplo de determinação de verdade, por exemplo, a oposição e as diferenças que se estabelecem entre os sujeitos; de um lado, o "homem", que se encontra em completa posição, do outro lado, a "mulher". Aqui se apresenta elemento de verdade em termos de sociedade, pois, em um país no qual a desigualdade se amplia, em diversos setores de classe sociais existem grupos sociais e gêneros em que isso se agrava, tornandose alvos de exploração ampliados e, principalmente, alvos de discriminação generalizada. Sobre esse fato, pode-se constatar, como na pesquisa de Cucolo (2019): "Brancos têm renda 74\% superior à de pretos e pardos", que, no Brasil, temos diversas perspectivas de diferenças que opõem os sujeitos. Entretanto, a mesma polaridade que se apresenta como dado de verdade pode ser convertida na forma de atuação paranoica, na qual essa categorização serve de heurística para se pensar todas as formas de condutas e relacionamentos entre os sujeitos. Nesse caso, essa polaridade não compreende as outras diversas possibilidades de combinações que existem em outras contradições no campo das relações humanas, pois "não adianta dizer o que se vê; o que se vê não habita jamais o que se diz" (DELEUZE; GUATTARI, 2014, p. 107).

As polaridades podem se dissolver, permitem-se analisar outras diversas contradições que se constituem no campo das relações humanas. Os casos de intolerâncias que se apresentam entre o "homem" e a "mulher" podem indicar que os extremos se apresentam em formas absolutas, mas isso não poderia impedir outras junções que contradizem a premissa da polaridade e, portanto, tornam possível pensar o sujeito de outros modos para além das categorizações.

Neste sentido, para se pensar o real, podem também ocorrer, no campo escolar, outras maneiras de analisar a indiferença perante o outro, que se opõem às verdades estabelecidas. Isso pode ocorrer em diversas circunstâncias em que se estabelece uma polaridade, em que de um lado se posiciona a vítima, e de outro, o carrasco. Nessa dinâmica, em termos de acusação, a posição do privilégio de saber e a subordinação do não saber impõe-se como algo atribuído naturalmente ao sujeito que se estabelece na posição da verdade.

Esse embaraço paranoico dos sujeitos nos deixa pensativos, no sentido de constituir o método investigativo para se compreender como e por qual motivo os sujeitos se acusam e o que é preciso para quebrar com o poder do "homem" que existe, mas frente a frente com grande parte dos "homens" que fazem 
também parte do sistema em que todos se encontram na posição de explorados. O questionamento é se não seria mais sensato anunciar qual sujeito aponta o dedo para outro e diz "você é homem privilegiado!" e se constitui como explorador do trabalho alheio numa sociedade segmentada em classes sociais na distribuição de renda no modelo da reprodução do capital.

Esse dedo que aponta para o outro e estabelece um discurso de verdade para o sujeito se constitui em narrativas numa forma de certeza, que já impede a construção do diálogo no sentido de ampliar a tolerância perante o outro. A intolerância é a matriz da burrice que se instaura no campo das relações humanas e nos impede, por completo, de realizar a atividade do pensamento crítico e, portanto, toda vez que escuto que não há tolerância, o que se constrói no lugar é a completa anulação do outro como sujeito. Entretanto, o que seria a burrice no sentido filosófico? Sobre isso, compreende-se que:

\begin{abstract}
A burrice é uma cicatriz. Ela pode se referir a um tipo de desempenho entre outros, ou a todos, a práticos e intelectuais. Toda burrice parcial de uma pessoa designa um lugar em que o jogo dos músculos foi, em vez de favorecido, inibido no momento do despertar. Com a inibição, teve início a inútil repetição de tentativas desorganizadas e desajeitadas. As perguntas sem fim da criança já são sinais de uma dor secreta, de uma primeira questão para a qual não encontrou resposta e que não sabe formular corretamente. [...]. Se as repetições já se reduziram na criança, ou se a inibição foi excessivamente brutal, a atenção pode se voltar numa outra direção, a criança ficou mais rica de experiência, como se diz, mas frequentemente, no lugar onde o desejo foi atingido, fica uma cicatriz imperceptível, um pequeno enrijecimento, onde a superfície ficou insensível. Essas cicatrizes constituem deformações. Elas podem criar caracteres, duros e capazes, podem tornar as pessoas burras - no sentido de uma manifestação de deficiência, da cegueira e da impotência, quando ficam apenas estagnadas, no sentido da maldade, da teimosia e do fanatismo, quando desenvolvem um câncer em seu interior. A violência sofrida transforma a boa vontade em má (ADORNO; HORKHEIMER, 1985, p. 121).
\end{abstract}

A burrice se amplia quando somos intolerantes com qualquer forma de manifestação de diferença. Portanto, a formação do intelectual se constitui na forma de ser tolerante em escutar o sujeito que perdeu a capacidade de sensibilidade e compreender no campo dos processos educativos: como alguém se torna o que é? (NIETZSCHE, 2001). Tal ideia, no modo dogmático de pensar o mundo, apresenta-se como mecanismo de defesa para não pensar em si mesmo como aquele que reifica o sujeito como objeto. 


\section{Resultado e discussão: a compreensão do campo pedagógico para além da aula em colapso}

Nessas condições, no campo das relações humanas, em qualquer forma de diálogo, ao se dizer "apesar de homem", poder-se-ia dizer que isso não se refere diretamente àquele que ocupa o lugar do privilegiado e, portanto, poderíamos estar juntos contra o inimigo comum que nos impõe a servidão e a exploração econômica - capitalismo mundial integrado (GUATTARI, 1981).

O contra-argumento da intolerância e do dogmatismo é algo vazio e serve apenas para aqueles que não pensam e, principalmente, não desejam pensar as contradições que se apresentam no real. Optam em não pensar e atuam em se tornarem mais rápidos em palavras de ordem, a dizerem para o outro suas certezas absolutas, que seria algo próprio da projeção de seus pensamentos não resolvidos que se encontram como verdadeiros pontos cegos e se apresentam como categorização.

Tentar abrir o diálogo é escutar a ampliação da intolerância, pois se não se aceita a acusação do privilégio, é porque não se compreende a si mesmo como privilegiado. Isso se apresenta como algo que gira em torno de si mesmo, cuja única saída é a posição da vítima que tem em si mesma a luta de libertar a todos do privilégio estabelecido, que não o aceita como lugar do outro.

Essas discussões que atravessam o campo escolar em atividades de sala de aula tornam-nas um verdadeiro colapso, no qual se rompe por completo o diálogo e se instaura a intolerância. Analiso que isso deveria ampliar os estudos sobre o conceito de privilégio, para se compreender todos os conjuntos de hierarquias que se estabelecem em discursos e formas de poder que também se encontram presentes em diversos movimentos sociais, sendo que, não por acaso, estamos vivendo um retrocesso político ampliado em todas as instâncias da sociedade.

A esperança seria que os movimentos sociais progressistas tivessem coragem de lidar com os erros e realizassem a crítica para romper com a visão dogmática. Talvez esse seja o mesmo problema que a ativista dos movimentos sociais Ângela Davis, que encontrou dificuldade na visita à cidade de São Paulo, em outubro de 2019, apresentou quanto ao esforço em sair da posição "Da sacralidade que muitos intelectuais adoram cultivar para si mesmos" (FRATESCHI; FERREIRA, 2019).

O que fica em evidência em não querer pensar o conceito como uma chave para compreender a realidade no campo da cultura escolar é a negação como forma contraditória do trabalho do pensamento, e isso seria o mecanismo de funcionamento do sintoma que é representado pelo "ponto cego", em não querer 
saber, ou na vontade de querer compreender a si, pois "Onde existe um sintoma, existe também uma amnésia, uma lacuna da memória, cujo preenchimento suprime as condições que conduzem à produção do sintoma" (FREUD, 1970, p. 21).

O grande ganho do capitalismo mundial integrado (GUATTARI, 1981) não é por nos conduzir no consumo de coisas, pois isso já se encontra plenamente estabelecido como forma de vida comum em que se coloca em movimento todo um conjunto de relações não críticas perante o mundo que nos cerca como sujeitos. O grande ponto de confronto diante do capital seria estabelecer uma ordem de resistência à divisão infinita que nos impede por completo de realizar qualquer forma de organização social de enfrentamento às diversas formas de exploração que se encontram em muitos campos da sociedade.

\section{Conclusão: alguns apontamentos para a construção de verdade, ou desconstruindo o privilégio como conviç̧ão de verdade, e a anulação do pensamento crítico}

Ao pensar as relações humanas, é interessante que se possa estabelecer uma forma horizontal de diálogo, em que nenhum tipo de hierarquia estabeleça outras formas de construção de verdade. Entretanto, o verdadeiro que transparece nas relações humanas seria o paradoxo de que somos atravessados por discursos da vontade, de poder e de verdade que nos posicionam no lugar do discurso como aquele que profere a palavra final. Partimos da compreensão de que

O importante, creio, é que a verdade não existe fora do poder ou sem poder (não é - não obstante um mito, de que seria necessário esclarecer a história e as funções - a recompensa dos espíritos livres, o filho das longas solidões, o privilégio daqueles que souberam se libertar). A verdade é deste mundo; ela é produzida nele graças a múltiplas coerções e nele produz efeitos regulamentados de poder. Cada sociedade tem seu regime de verdade, sua "política geral" de verdade: isto é, os tipos de discurso que ela acolhe e faz funcionar como verdadeiros; os mecanismos e as instâncias que permitem distinguir os enunciados verdadeiros dos falsos, a maneira como se sanciona uns e outros; as técnicas e os procedimentos que são valorizados para a obtenção da verdade; o estatuto daqueles que têm o encargo de dizer o que funciona como verdadeiro (FOUCAULT, 1990, p. 12). 
$\mathrm{Na}$ questão da verdade, o ponto central seria estabelecer uma relação de igualdade entre aquele que pronuncia a palavra e o outro que a recebe. A ordem pronunciada na gramática imperativa encontra-se pautada numa concepção de desigualdade em que, portanto, o outro não sabe e resta somente a condição da obediência cega, que interdita por completo a possibilidade de emancipação do sujeito.

Desse modo, a mensagem direta de primeira ordem em que se pronuncia a pretensão de verdade - "você é privilegiado" - impõe-se diretamente na hierarquia entre aquele que manda e o outro que obedece e, principalmente, cria a impossibilidade de qualquer ação reflexiva.

Analisamos que indicar ao outro seu lugar se apresenta como o paradoxo da verdade, que, em seu simples detalhe, pode revelar a ponta do iceberg que anuncia toda lógica de perda de sensibilidade que atravessa a formação escolar no campo da instituição escolar em sua estrutura e funcionamento. Nesses termos, no lado da emancipação do sujeito por uma relação de igualdade, dever-se-ia compreender que

O problema do mestre emancipador é, portanto: como fazer com que aquele que tem diante de si ultrapasse a única barreira que conta - não entre as culturas, entre o universal e o particular, entre a ignorância e o saber - mas a barreira entre aqueles que têm a opinião da igualdade e os que têm a opinião da desigualdade? $\mathrm{O}$ emancipador não é alguém que vai ao encontro das pessoas para emancipá-las. A emancipação sempre supõe um processo em que alguém quer passar e, assim, a questão é saber o que passar vai querer dizer (VERMEREN; CORNU; BENVENUTO, 2003, p. 196).

Trata-se de compreender os efeitos formativos do sujeito e sua ocorrência, no interior das unidades de ensino na constituição do sujeito do conhecimento, numa ruptura completa da hegemonia pautada na concepção de ciência neutra e explicativa. Neste campo, deveríamos ficar atentos às diversas proposições pedagógicas, na era da pós-verdade, que se encontram presentes na unidade escolar e que nos educam desde muito tempo a não duvidar e, principalmente, a não pensar criticamente o mundo em nossa volta.

Podemos indicar que a posição do "mestre explicador" (RANCIÈRE, 2002) torna-se exemplo de como devemos evitar um tipo de discurso de verdade que nos impede de acessar o outro como aquele que possui inteligência em sua forma de pensar. Para romper com a figura intolerante e dogmática, seria 
prudente compreendermos, primeiramente em nós mesmos, os nossos pontos cegos e como isso afeta o nosso modo de pensar e as nossas relações com a vida na sociedade. Nesse voltar a si mesmo para o ponto cego, encontra-se o entorno da questão primordial da função do intelectual que se encontra no exercício constante de pensar o não saber. Aqui se encontra uma proposição pedagógica que enfrenta a pós-verdade, sem medo de pensar na diversidade de discursos de verdade, e isso está na possibilidade de destituir qualquer forma de relação que se estabeleça nas hierarquias do poder.

Para Rancière (2002), fica estabelecido um conjunto de ações de modo analítico ao se compreender as diversas possibilidades de proposição pedagógica que façam o giro entre aquele que sabe e o outro que não sabe, em que a função do sujeito intelectual seria um modo específico de pensar.

Nessa proposição pedagógica no mundo da pós-verdade, o que se radicaliza seria a premissa da condição da oposição entre o educar e a competência técnica que se apresenta como certo transtorno, mais propriamente como o surgimento do "[...] embrutecimento explicador. Há embrutecimento quando uma inteligência é subordinada a outra inteligência" (RANCIÈRE, 2002, p. 31). Como educador, desejo uma forma de transmissão de saber que nos ensine a pensar o mundo na pós-verdade e, para tanto, o ato pedagógico se torna pleno como forma de destituir a convicção de verdade como modo de produção do pensamento crítico e, portanto, como uma atividade de construção que se torna presente em diversos modos de compreensão sobre o mundo e no pleno sentido da ampliação da tolerância perante a discordância.

\section{REFERÊNCIAS}

ADORNO, Theodor; HORKHEIMER, Max. A dialética do esclarecimento: fragmentos filosóficos. Rio de Janeiro: Jorge Zahar, 1985.

CUCOLO, Eduardo. Brancos têm renda $74 \%$ superior à de pretos e pardos. Folha de S. Paulo, São Paulo, 2019. Disponível em: https://www1.folha.uol.com.br/ mercado/2019/11/brancos-tem-renda-74-superior-a-de-pretos-e-pardos-diz-ibge.shtml. Acesso em: 13 nov. 2019.

DELEUZE, Gilles; GUATTARI, Félix. Mil platôs: capitalismo e esquizofrenia. Tradução de Ana Lúcia de Oliveira. Rio de Janeiro: Editora 34, 2014.

FEDOSSEIEV, P. N. et al. Karl Marx: biografia. Lisboa: Edições Avante, 1983. 
FOUCAULT, Michel. Microfísica do poder. Tradução de Roberto Machado. Rio de Janeiro: Graal, 1990.

FRATESCHI, Yara; FERREIRA, Laíssa. Ângela Davis, a filósofa na cidade. Le Monde Brasil Diplomatique, São Paulo, 25 out. 2019. [Seção] Razão Prática, Razão Teórica. Disponível em: https://diplomatique.org.br/angela-davis-a-filosofa-na-cidade/. Acesso em: 29 out. 2019.

FREUD, Sigmund. Cinco lições de psicanálise (1910 [1909]). In: FREUD, Sigmund. Obras completas. Tradução de Jayme Salomão. Rio de Janeiro: Imago, 1970. v. xi.

FREUD, Sigmund. Lo siniestro [1919]. In: FREUD, Sigmund. Obras completas Sigmund Freud. Tradução de Luis López-Ballesteros y de Torres. Madrid: Biblioteca Nueva, 1996. v. iii.

FREUD. Sigmund. O mal estar na cultura. Tradução de Renato Zwick. Porto Alegre: L\&PM, 2010.

GHIRALDELLI JR., Paulo. A filosofia como desbanalização do Brasil. Entretextos, Teresina, 10 nov. 2011. Disponível em: https:/www.portalentretextos.com.br/index.php/ post/a-filosofia-como-desbanalizacao-do-brasil. Acesso em: 10 out. 2019.

GUATTARI, Félix. Revolução molecular: pulsações políticas do desejo. Tradução de Suely Belinha Rolnik. São Paulo: Brasiliense, 1981.

KOSIK, Karel. O mundo da pseudoconcreticidade e a sua destruição. In: KOSIK, Karel. Dialética do concreto. Tradução de Célia Neves e Alderico Toríbio. Rio de Janeiro: Paz e Terra, 1976.

LAJONQUIÈRE, Leandro de. De Piaget a Freud: a (psico)pedagogia entre o conhecimento e o saber. 3. ed. Petrópolis: Vozes, 1992.

LAJONQUIÈRE, Leandro de. Infância e ilusão (psico)pedagógicas: escritos de psicanálise e educação. Petrópolis: Vozes, 1999.

MARX, Karl. Introdução à crítica da economia política. In: MARX, Karl. Contribuições à crítica da economia politica. Tradução de Maria Helena Barreiro Alves. 2. ed. São Paulo: Martins Fontes, 1983.

NIETZSCHE, Friedrich. Humano, demasiado humano: um livro para espíritos livres. Tradução de Paulo César de Souza. São Paulo: Companhia das Letras, 2000.

NIETZSCHE, Friedrich. Como alguém se torna o que é. Tradução de Paulo César de Souza. 2. ed. São Paulo: Companhia das Letras, 2001.

RANCIÈRE, Jacques. O mestre ignorante: cinco lições sobre a emancipação intelectual. Tradução de Lílian do Valle. Belo Horizonte: Autêntica, 2002.

RODRIGUES, Rogério. Apontamentos críticos referentes à cartografia sobre a compreensão em ser professor de verdade a partir de Jacques Rancière. Revista Ciências Humanas UNITAU, Taubaté, v. 13, n. 1, p. 48-55, jan./abr. 2020. 
ROUDINESCO, Elisabeth; PLON, Michel. Dicionário de psicanálise. Tradução de Vera Ribeiro e Lucy Magalhães. Rio de Janeiro: Jorge Zahar, 1998.

VERMEREN, Patrice; CORNU, Laurence; BENVENUTO, Andrea. Atualidade de O mestre ignorante. Educação \& Sociedade, Campinas, v. 24, n. 82, p. 185-202, abr. 2003. Disponível em: http://www.scielo.br/scielo.php?script=sci_arttext\&pid=S010173302003000100009\&lng=pt\&nrm=iso. Acesso em: 13 nov. 2019.

Texto recebido em 10/08/2020.

Texto aprovado em 15/06/2021. 